\section{Roberto Filizola}

Universidade Federal do Paraná, UFPR

Email: robertofilizola@gmail.com

(D) http://orcid.org/0000-0003-4125-5491
Recebido em: 29/08/2017

Aprovado em: 21/02/2018

\section{Certo mal-estar povoa o território da educação geográfica: colocando à prova o modelo de transposição didática}

\section{Roberto Filizola}

\section{Resumo}

Os saberes com os quais alunos e professores trabalham em sala de aula parecem assumir um distanciamento crescente entre o proposto e o efetivamente realizado, resultando em frustação. Paradoxalmente, à Geografia é atribuído um potencial formativo que lhe assegura realce no grupo das disciplinas escolares, situando-a como um campo por excelência da multidisciplinaridade. A Geografia estabelece uma interface com vários ramos do saber e chama a atenção por lidar com temas e conteúdos que emergem dos mundos físico e social, do material e do ideal. À semelhança de um novelo de lã, a crise do ensino da Geografia apresenta várias meadas, capazes de obstaculizar a inovação ou o avanço na educação geográfica. O problema residiria nos conteúdos? Seu ensino encontra-se descolado da dimensão de um educar geograficamente? A relação ensino-aprendizagem resulta em saberes minimamente apropriados pelos alunos? No presente artigo, propomo-nos a fazer uma reflexão acerca dos encontros e desencontros na educação geográfica a partir da problematização da relação entre a disciplina escolar e a geografia universitária. Para tanto, valer-nos-emos dos conceitos de cultura escolar e de saber docente para alicerçar a tese de que uma revitalização da educação geográfica capaz de assegurar a formação de uma cidadania crítica deve necessariamente colocar à prova o modelo de transposição didática, no qual a disciplina escolar é concebida como um receptáculo passivo do conhecimento produzido no campo acadêmico, além de situar o professor como um mero reprodutor desse conhecimento.

Palavras-chave: Cultura escolar. Geografia escolar. Transposição didática. 


\section{Abstract}

\section{Keywords:}

Didactic transposition. School culture. School geography.

\section{Resumen}

\author{
Palabras clave: \\ Transposición \\ didáctica. Cultura \\ escolar. Geografía \\ escolar.
}

\section{A certain disconfort populates the territory of geographical education: putting to the test the model of didactic transposition}

The knowledges with which students and teachers work in the classroom seem to assume a growing distance between the proposed and the effectively realized, resulting in frustration. Paradoxically, geography is attributed a formative potential that ensures it is highlighted in the group of school subjects, placing it as a field par excellence of multidisciplinarity. Geography establishes an interface with various branches of knowledge and draws attention by dealing with themes and contents that emerge from the physical and social worlds, the material and the ideal. Like a ball of wool, the crisis of the teaching of Geography presents several skeins, capable of hindering innovation or advancement in geographic education. Would the problem lie in the contents? Does your teaching find itself detached from the dimension of a geographically educating? Does the teaching-learning relationship result in knowledge that is minimally appropriate for students? In the present article we propose a reflection about the meetings and disagreements in the geographic education from the problematization of the relation between the school discipline and the university geography. Therefore, we will be using the concepts of school culture and teacher knowledge to support the thesis that a revitalization of geographic education capable of ensuring the formation of critical citizenship must necessarily put to the test the model of didactic transposition in which the School discipline is conceived as a passive receptacle of knowledge produced in the academic field, besides situating the teacher as a mere reproducer of that knowledge.

\section{Un cierto malestar pobla el territorio de la educación geográfica: poniendo} a prueba el modelo de transposición didáctica

Los saberes con los que alumnos y profesores trabajan en el aula parecen asumir un distanciamiento creciente entre lo propuesto y lo efectivamente realizado, resultando en frustación. Paradójicamente, a la Geografía se le atribuye un potencial formativo que le asegura realce en el grupo de las disciplinas escolares, situándola como un campo por excelencia de la multidisciplinariedad. La Geografía establece una interfaz con varias ramas del saber y llama la atención por tratar con temas y contenidos que emergen de los mundos físico y social, del material y del ideal. Al igual que un hilo de lana, la crisis de la enseñanza de la geografía presenta varias medias, capaces de obstaculizar la innovación o el avance en la educación geográfica. ¿El problema residía en los contenidos? ¿Su enseñanza se encuentra descolgada de la dimensión de un educar geográficamente? La relación enseñanza-aprendizaje resulta en saberes mínimamente apropiados por los alumnos? En el presente artículo nos proponemos una reflexión acerca de los encuentros y desencuentros en la educación geográfica a partir de la problematización de la relación entre la disciplina escolar y la geografía universitaria. Para ello, estaremos valiéndonos de los conceptos de cultura escolar y de saber docente para fundamentar la tesis de que una revitalización de la educación geográfica capaz de asegurar la formación de una ciudadanía crítica debe, necesariamente, poner a prueba el modelo de transposición didáctica en el cual la disciplina escolar es concebida como un receptáculo pasivo del conocimiento producido en el campo académico, además de situar al profesor como un mero reproductor de ese conocimiento. 


\section{Introdução}

Não é de hoje que circula pelo mercado editorial um volume não desprezível de livros, coletâneas e artigos científicos a respeito do ensino de Geografia, abordando uma diversidade de questões de cunho teórico e metodológico. Contudo, tal volume contrasta com o reduzido número de linhas de pesquisa em ensino de Geografia nos Programas de Pós-Graduação, sejam eles em Geografia ou em Educação. Como esse paradoxo repercute na renovação do status da disciplina escolar Geografia no currículo da Educação Básica? É no contexto dessa problemática, ou em outras palavras, da crise do seu ensino, que o modelo transpositivo é abordado no presente trabalho.

Nessa perspectiva, é interessante observar que a crise do ensino da Geografia Escolar integra desde longa data os debates que se desenrolam em eventos promovidos por entidades de classe, como a Associação dos Geógrafos Brasileiros (AGB), através do Fala Professor, e por instituições de ensino e pesquisa, organizadoras de encontros, por exemplo, acerca da prática de docência, como o Encontro Nacional de Prática de Ensino de Geografia (Enpeg). As secretarias de educação, tanto na esfera municipal como na estadual, também se inserem nesses debates, mesmo porque atuam de maneira direta na reformulação curricular da Educação Básica. Afora isso, políticas provenientes da esfera federal também incidem sobre os aspectos mencionados, a exemplo das reformas curriculares da Educação Básica e da normatização do processo de formação de professores. Quer dizer, a formação inicial e continuada de professores, a relação entre teoria e prática no ensino, a seleção e organização de conteúdos escolares, o currículo e a viabilidade metodológica dos programas escolares são temas que perpassam a referida crise. Quais os avanços advindos desses fóruns e como afetam a sala de aula de Geografia?

Convém recordar, ainda, que a escola, particularmente a pública, é um território específico. Sua especificidade produz territorialidades cujos contornos se definem e redefinem a partir das relações travadas por seus atores sociais, pelos interesses por eles perseguidos e pelos desideratos básicos da escola. Sendo assim, instrução e formação constituem forças que, a um só tempo, aglutinam os atores sociais e promovem conflitos entre si. Embora a organização da escola esteja voltada para o desempenho desse papel, não se pode perder de vista que as diferenças sociais e culturais presentes no cotidiano escolar ganharam relevo nos últimos tempos, reclamando seu enfrentamento em novas bases. Diante dessa problemática, qual a função social dos conhecimentos produzidos pela ciência geográfica e como eles são concebidos para o seu ensino?

Somem-se a essas considerações iniciais acerca da crise do ensino da Geografia dois cenários até há pouco tempo considerados implausíveis. O primeiro deles é uma referência à reforma do Ensino Médio. A nova legislação não faz menção à obrigatoriedade do ensino de Geografia (e de História) nos três anos que configuram essa etapa da Educação Básica, além de estabelecer uma mudança na grade curricular que possibilitará aos estudantes a opção por matérias de áreas de seu interesse. O segundo diz 
respeito ao processo de encerramento de dois cursos de licenciatura, ocorrido em Curitiba, Paraná. A redução na procura pelo curso na Universidade Tuiuti do Paraná (UTP) foi o fator responsável pelo fim do seu funcionamento. A ênfase nas licenciaturas em vez de nos cursos formadores de tecnólogos foi apontada como responsável pela queda no faturamento, gerando demissões e o fechamento de cursos nas Faculdades Integradas Espíritas, dentre os quais o de Geografia. Essa questão possui uma dimensão política significativa e que pode afetar o "sucesso" da disciplina escolar. Por outro lado, reforça o sentido que se pode atribuir ao currículo: constructo sócio-histórico, cujos sujeitos disputam recursos, status e territórios, conforme Goodson (1995). A Geografia enquanto disciplina escolar pode ser considerada 'longeva'. Diante desses cenários, sua posição na grade curricular da Educação Básica no país se manterá estável e segura?

As possibilidades de a disciplina escolar Geografia permanecer ainda por um período de tempo não desprezível na grade curricular são grandes. Segmentos vários da sociedade atribuem à disciplina certo status e relevância social, conferindo-lhe legitimidade. Nesse aspecto, uma outra contradição pode ser identificada, desta vez no seu ensino. Isso porque determinados conteúdos da disciplina, tomados como 'imprescindíveis', ainda são ensinados juntamente com outros, considerados 'novos'. Quer dizer, de um lado, temas escolares de considerável tradição, desde a memorização de capitais até a confecção mecânica de mapas, passando pela conceituação de 'acidentes geográficos' sem qualquer vínculo com a realidade, até o uso de uma nomenclatura acadêmica atribuída às partes que compõem a natureza, porém uma 'natureza selvagem'. De outro lado, a incorporação de temas contemporâneos, como a nova ordem mundial, os tecnopólos nacionais, os problemas ambientais e urbanos, preconceitos de origem geográfica. A insistência na veiculação de informações por demais elementares e que tomam o espaço de proposições com elevado potencial de formação humanística coloca em xeque a importância educacional da Geografia. O já desgastado questionamento 'para que serve ensinar Geografia?’ necessita ser confrontado com a relação com o saber, sobretudo quando a referência são os educandos das classes menos favorecidas, moradores de zonas periféricas. Desde sempre o ser humano encontra-se submetido à obrigação de aprender. Aprender para quê? Nessa perspectiva, é inegável a necessidade de uma reflexão crítica acerca do papel e da importância da Geografia Escolar. Mais do que isso, daquilo que lhe compete no âmbito da relação com o saber.

\section{Ensino da Geografia, cultura escolar e saber docente}

Carlos Miguel Delgado de Carvalho foi professor e autor de livros científicos e didáticos. Em sua obra Methodologia do ensino geographico: introdução aos estudos de Geographia Moderna, publicada em 1925, o autor registra sua crítica aos métodos de ensino e seu esforço pela edificação de uma 
Geografia Escolar em bases mais avançadas do que aquelas em vigor na época. Nesse contexto, fica a impressão de que a crise do seu ensino já existia de longa data. Senão, vejamos:

\begin{abstract}
A geographia tem por objecto o estudo da terra como "habitat" do homem. Infelizmente não é sob este ponto de vista que é estudado entre nós este ramo scientifico. Nas escolas do Brasil e de outros paizes de nosso continente, a geographia é o estudo de uma das modalidades da imaginação humana, isto é, da sua faculdade de attribuir nomes, de chrismar areas geographicas. As montanhas, os rios as regiões naturaes não são estudados em si, mas apenas como merecedores de um esforço de nossa fantasia. Aqui, quem não sabe nomenclatura não sabe geographia, e deste modo a poesia e a geographia são productos directos da imaginação, apesar de fazerem parte de cadeiras diferentes. Uma geographia é tida por mais ou menos completa, segundo o numero de paginas que conta e a extensão das listas que a imaginação confia á memoria das victimas; o ideal seria provavelmente um tratado volumoso, incluindo a lista telephonica. Entrariamos assim no domínio pratico [sic]. (CARVALHO, 1925, p. 3-4).
\end{abstract}

Ainda que o foco no momento seja a importância da Educação Geográfica, as palavras de D. Carvalho possibilitam uma leitura de importantes aspectos da história da disciplina escolar Geografia no Brasil. Segundo ele, ao mesmo tempo em que fica evidente a carência de uma proposição de ensino que fosse útil aos alunos e não se restringisse à mera memorização dos elementos da paisagem, a defasagem entre o saber acadêmico e aquilo que se ensinava nas aulas de Geografia era gritante. Quer dizer, D. Carvalho recorria à ciência de referência para enformar um ensino de Geografia em novas bases. Como não poderia deixar de ser, nesse contexto de reformulação da disciplina também foi considerada a finalidade da Geografia Escolar. Seguindo particularmente as tendências em voga na Europa, D. Carvalho julgava que a Geografia era uma disciplina pátria por excelência. Em outras palavras, era-lhe confiada a função de incutir nas novas gerações a ideologia do nacionalismo patriótico. Não à toa, era nas aulas de Geografia que se proporcionava a disseminação de imagens e símbolos que reforçavam tal ideologia. É o caso da utilização de mapas, sobretudo os do Brasil, fossem eles decalcados nos cadernos dos alunos, fossem dependurados nas salas de aula. Sendo assim, conteúdos, imagens e símbolos eram trabalhados de forma a consolidar a ideia e o sentimento de uma pátria una e indivisível.

Faz-se necessário recordar que ao término do século XIX e princípio do XX a população brasileira era relativamente pequena diante da imensidão do território nacional. Afora isso, uma parcela não desprezível dessa população era constituída por africanos, afrodescendentes, indígenas, além, evidentemente, da crescente presença de imigrantes estrangeiros, notadamente os de origem europeia. Não resta dúvida de que esses habitantes não se sentiam brasileiros, tampouco comungavam dos mesmos valores ou compartilhavam de um passado comum. Ao contrário, determinados grupos resistiram ao processo de aculturação, haja vista as escolas localizadas nas colônias alemãs do Sul, onde as aulas eram ministradas em alemão. Grupos como os dos nipônicos adentravam o país na certeza de que retornariam ao seu país de origem, razão pela qual se empenhavam em preservar sua cultura. Foi nesse contexto, portanto, que o projeto nacional idealizado pela classe dominante, aí inclusa a construção de uma 
comunidade imaginada, de acordo com Anderson (2008), foi posto em ação valendo-se para tanto da implantação de um sistema de ensino que cobrisse todo o território nacional.

A atribuição do papel de difusora de valores pátrios permaneceu colada à Geografia Escolar durante um largo período de tempo. Em plena década de 1970, por exemplo, os manuais didáticos traziam estampadas mensagens de forte cunho ideológico, como no caso das obras de Aroldo de Azevedo, um dos primeiros professores de Geografia formado pela Universidade de São Paulo (USP) e autor de dezenas de obras didáticas. Em O Brasil e suas regiões, é plenamente reconhecível o projeto nacionalista se perpetuando através da Escola, mais especificamente pelas aulas de Geografia:

Assim é O Brasil e suas regiões, elaborado com carinho e dentro da fé inquebrantável que temos nos destinos reservados ao nosso País. Que seja útil a quantos o compulsarem. E que, através de suas páginas, consiga transmitir o mesmo amor e a mesma confiança na Pátria que nos é comum una e indivisível, grande potência do século XXI (AZEVEDO, 1972, Apresentação).

Fosse movido por interesses tais como os da aristocracia rural da República Velha ou os dos ideólogos do regime militar de 1964, fosse por forças democráticas e progressistas pré e pós-ditadura militar, o desenho resultante dos programas escolares de Geografia manteve uma estrutura muito peculiar e que pouco se alterou ao longo desse período. Melhor dizendo, a arquitetura curricular espelhava um projeto, o projeto da classe dirigente. A seleção e a organização dos conteúdos se davam de modo tal a viabilizar a consecução dos 'destinos reservados ao nosso País", como na declamação de Aroldo de Azevedo. Assim como o projeto da classe dirigente se perpetuou, as questões socioeconômicas mantiveram-se em um cenário de tensões e conflitos, ou seja, o ‘currículo oculto' das elites nacionais também frutificou.

As graves distorções da distribuição da riqueza produzida, seja no campo ou na cidade, configuraram uma espécie de pano de fundo na definição das novas finalidades e objetivos do ensino da Geografia a partir da década de 1980. Nesse contexto, a disciplina escolar passou a ser pensada e colocada a serviço da superação do quadro de graves dificuldades a que a sociedade nacional encontravase submetida. Assim, o movimento de renovação da ciência geográfica no Brasil produzido em pleno processo de luta pela redemocratização da sociedade brasileira, em finais dos anos de 1970, teve desdobramentos nos programas escolares de Geografia. Contudo, a carência em termos de viabilidade metodológica, entre outros aspectos, resultou em avanços pouco expressivos. Isso não significa dizer que os propósitos de seu ensino não tenham resultado em quaisquer melhorias. Inversamente, muitas luzes foram lançadas. Consequentemente, à Geografia Escolar foi atribuída uma outra finalidade, um outro objetivo, que embora amplo e geral, pode ser tomado como algo 'mais nobre, mais refinado'. Trata-se do desenvolvimento do raciocínio geográfico e da formação da consciência espacial, uma proposição para seu ensino tanto no Brasil como noutras partes do mundo (CAVALCANTI, 2002; LACOSTE, 1988; MÉRRENE-SCHOUMAKER, 1999). 
Embora tal finalidade ainda enfrente alguns obstáculos para sua implantação no ambiente escolar, haja vista as limitações impostas por sua reduzida viabilidade metodológica, mais especificamente pela falta de clareza para o conjunto dos docentes da disciplina - afinal, o que são e como proceder de um ponto de vista pedagógico para que o raciocínio geográfico e a consciência espacial se convertam em uma prática pedagógica verdadeiramente geográfica? -, é inegável o quanto significa em termos de avanço. De fato, proporcionar situações em que os educandos pensem o espaço e tomem consciência da espacialidade das coisas, representa um expressivo descolamento da ideia caricata de 'disciplina da decoreba', tão presente no imaginário das pessoas comuns. Afinal, a Matemática Escolar parece desfrutar de um certo status, daí auferir uma carga horária na grade curricular maior, decorrente, ao que parece, das suas finalidades de ensino, dentre as quais perseguir o desenvolvimento do raciocínio lógico. É líquido e certo que a história da Matemática enquanto conhecimento possui elementos ainda mais plausíveis acerca do reconhecimento da disciplina, mas o simples fato de não permitir que sua finalidade estivesse restrita às quatro operações e, destarte, que à memorização da tabuada fosse atribuída sua identidade, contribuiu para tal.

Assim posto, é lícito argumentar que, do mesmo modo que a formação de uma consciência ambiental ou ecológica tem sido reclamada pela sociedade, justificando e legitimando a presença de uma educação ambiental no currículo escolar, por que não assumir a formação da consciência espacial dentro dos propósitos e finalidades da Educação Geográfica na escola? Por que a disciplina deve encampá-la?

Inicialmente, é de todo recomendável destacar que se trata de uma questão ou dimensão específica do currículo, conforme já mencionado anteriormente. Isso posto, fica evidenciado tratar-se de um movimento no sentido de manter a Geografia Escolar 'viva', assumindo um papel social apropriado ao momento histórico presente, além de significar que as novas tendências do pensamento geográfico também são uma referência para a elaboração dos objetivos e finalidades acima citados. Afora isso, significa a abertura de um caminho para se evadir das justificativas ou amplas demais - conhecer o mundo, formar cidadãos críticos e atuantes -, ou vagas e incompletas, que tão somente fazem apequenar o lugar da disciplina na escola e na sociedade. Mesmo porque não são poucos os que associam a disciplina ao papel de tão somente ensinar o aluno a se localizar, a usar mapas e a orientar-se.

O desenvolvimento do raciocínio geográfico e a formação de uma consciência espacial dizem respeito ao olhar geográfico, à maneira particular de a Geografia ler o mundo, estudar a sociedade. Se de fato a ciência geográfica é uma ciência humana, compete-lhe compreender a dimensão espacial da sociedade (SANTOS, 1996). Nessa perspectiva, é deixada para trás a concepção perseguida por D. Carvalho, a de um ramo científico que "tem por objeto o estudo da terra como 'habitat' do homem". Por outro lado, seria plausível atribuir um objeto de estudo para a disciplina, isto é, "o estudo da organização do espaço pela sociedade humana", algo tão em voga? Ou caberia à disciplina na escola um objeto de 
conhecimento, ou, nas palavras de Diamantino Pereira, um "instrumento concreto de conhecimento"? (PEREIRA, 1996)?

Proporcionar um "letramento socioespacial" ou uma "alfabetização geográfica" que instrumentalizasse os educandos de modo a situarem-se no mundo e nele melhor agirem parecem ser finalidades significativas para o ensino da disciplina. Contudo, o processo de construção de propostas curriculares de Geografia ocorrido nos últimos 30 anos defrontou-se com desafios e dificuldades de árdua superação. Mesmo porque o território escolar encontra-se imerso em uma cultura específica, a cultura escolar. Nesse sentido, é importante destacar, a estrutura e a organização administrativo-pedagógica presentes na atualidade foram gestadas no início do século XX, resultando na institucionalização de um modelo escolar caracterizado pela "organização de grupos homogêneos em classes graduadas, o ensino simultâneo, a graduação dos estudos e a organização rígida e controlada do tempo" (PERES, 2010, p .60). Isso corresponde a dizer que a cultura escolar, isto é, “[...] toda a vida escolar, fatos e ideias, mentes e corpos, objetos e condutas, modos de pensar, dizer e agir" (FRAGO, 1995 apud VIDAL, SCHWARTZ, 2010, p. 22) é construída e também reinventada.

No processo de construção e/ou reinvenção da cultura escolar, os sujeitos que atuam mais especificamente com uma prática em sala de aula, os professores, e os sujeitos que lidam mais diretamente com a gestão pedagógica e a organização da escola, os gestores, desenvolvem estratégias de ação que se inserem em um contexto de negociação e conflito. Nesse contexto, é essencial salientar que a dimensão prática da cultura escolar possui um componente necessário à compreensão do ensino das disciplinas escolares: o saber docente. Monteiro (2002, p. 137), expressando o pensamento de Tardif, Lessard e Lahaye, sintetiza que "o saber docente [é] heterogêneo e plural por ser constituído dos saberes das disciplinas, dos saberes curriculares, dos saberes da formação profissional e dos saberes da experiência". Nessa perspectiva de valorização, e não de desqualificação do saber docente, a autora salienta ainda que a experiência é "um conjunto de vivências significativas através das quais o sujeito identifica, seleciona, destaca os conhecimentos necessários e válidos para a atividade profissional e exclui aqueles não validados pela sua própria ação" (MONTEIRO, 2002, p. 138). E conclui: “a ação docente é um processo de construção, e não de reprodução de modelos prontos" (MONTEIRO, 2002, p. 140). Daí ser na sala de aula, seu ponto de chegada, o local em que as reformas curriculares se efetivam ou não. As resistências oferecidas pelos professores diante das mudanças oriundas de instâncias superiores, portanto, têm que, necessariamente, ser estimadas. Isso posto, faz-se necessário rever como a disciplina escolar e a disciplina universitária se constituem. 


\section{Constituindo-se em disciplina escolar e disciplina universitária}

De definição e de constituição aparentemente banais, as disciplinas escolares quando remetidas aos contextos históricos que as originaram, adquirem uma dimensão, ou melhor, situam-se em um campo específico, que demanda a reinterpretação de sua natureza. A pesquisa histórica refuta a ideia de que a disciplina escolar enquanto conhecimento seja cópia simplificada dos saberes produzidos pela pesquisa. Assim, as disciplinas escolares "têm seu tempo de elaboração, de crescimento ou de declínio, em função dos saberes disponíveis e das necessidades da sociedade" (BRUTER; LOCHER, 2011, p. 239). Daí que precisar os primórdios daquilo que se possa supostamente julgar como pertinente ao ensino da Geografia Escolar, seja no Brasil ou noutros países, não pode ser tomado como tarefa fácil. $\mathrm{O}$ mesmo se aplica à disciplina universitária, notadamente na Europa.

Tomando-se como referência a obra Uma história social do conhecimento, de Peter Burke, na qual o historiador social e cultural britânico examina como a classificação do conhecimento acadêmico adentrava a prática cotidiana das universidades europeias, os currículos, as bibliotecas e as enciclopédias são analisados como "uma espécie de tripé intelectual" (BURKE, 2003, p. 83), dentro do sistema de conhecimento. Servindo-se das metáforas criadas no passado, representadas por meio de ilustrações em que a organização do conhecimento aparece hierarquicamente distribuída, o autor reproduz em sua obra os desenhos originais, formados por árvores e galhos, e assim os interpreta: "Pensar em termos de árvores sugere uma distribuição entre o dominante e o subordinado, tronco e galhos [...] até as raízes e brotos, flores e frutos" (BURKE, 2003, p. 83).

Segundo o historiador, a Geografia já constava na ordem das bibliotecas antigas, como na bibliografia impressa de Conrad Gesner, de 1548, bem como nas enciclopédias chinesas das dinastias Ming e Qing. Quanto às disciplinas dos currículos das universidades, a Geografia tornou-se mais visível no século XVI: “A geografia, também conhecida como cosmografia, era outra disciplina que ganhava proeminência na universidade no início do período moderno, assim como nos colégios jesuítas" (BURKE, 2003, p. 94).

A essa altura, revela-se necessário retomar o diálogo entre as disciplinas escolares e universitárias em uma perspectiva histórica. Muito embora as concepções de escola e de universidade na contemporaneidade em muito se difiram das do início do período moderno, importa salientar que se está diante de instituições historicamente construídas, ou seja, que atendem a interesses e necessidades próprias de uma época. A esse respeito, Burke (2003, 82), uma vez mais empregando a metáfora da árvore, salienta que

A imagem da árvore ilustra um fenômeno central em história cultural, a naturalização do convencional, ou a apresentação da cultura como se fosse natureza, da invenção como se fosse descoberta. Isso equivale a negar que os grupos sociais sejam responsáveis pelas classificações, assim sustentando a reprodução cultural e resistindo a tentativas de inovações. 
Enquanto disciplina universitária, a Geografia adquire progressivo relevo por conta da expansão comercial desenvolvida a partir da Península Ibérica, que contou, na sequência, com a participação de outros atores internacionais. Nesse contexto, em que o marco temporal e espacial é representado pelo período moderno na Europa Ocidental e, portanto, dele são excluídos os contextos mais remotos, experienciados por gregos, romanos, árabes e chineses, observa-se certo vínculo entre a disciplina universitária e a escola, uma e outra estreitamente submetidas às altas esferas do poder. O que se ensinava e para que se ensinava, portanto, diziam respeito à formação de uma elite dirigente, bem como ao domínio e controle de novos espaços em um período de exploração e império. Assim colocada, a expansão do horizonte geográfico proporcionou o amadurecimento de certos ramos do conhecimento, criando as condições históricas para a conformação, no caso, da Geografia Moderna. Contudo, é inevitável dizer que, no processo de constituição da Geografia enquanto disciplina universitária, o prestígio de outros campos e a seriedade com que certos conhecimentos foram produzidos pelos gregos e romanos antigos contaram sobremaneira para seu ingresso na universidade. Como bem esclarece Burke (2003, p. 95), “a Geografia era às vezes ensinada pelo professor de astronomia, sugerindo que o novo tema entrou na universidade com mais facilidade porque vinha na esteira de uma disciplina estabelecida".

Quanto ao ensino escolar, a Geografia já guardava estreitas relações com o poder do Estado em fins do século XVIII e no transcurso do XIX. Vale recordar que, na França, por exemplo, a queda da Bastilha e a decorrente assumpção dos principais ideais da Revolução Francesa, de liberdade, igualdade e fraternidade, influenciaram sobremaneira a edificação de uma escola de fato pública e para todos. No particular caso da Alemanha, a instrução pública foi da máxima relevância. Como se sabe, o processo de unificação que resultou na Alemanha deu-se através do controle político e econômico exercido pela Prússia na Confederação Alemã. É interessante observar que “em 1763, Frederico II foi responsável por uma audaciosa inovação no absolutismo prussiano, com a instituição do ensino primário obrigatório para toda a população masculina" (PEREIRA, 1999, p.4 1). Decorridos cerca de 100 anos, já vigorava na Alemanha um sistema escolar organizado e hierarquizado do Ensino Maternal ao Ensino Médio. Dentre suas disciplinas, a Geografia adquiria um valor crescente. Conforme Pereira (1999), "a Geografia se fez presente em todos os níveis e centros de ensino. Para ingressar nos centros de ensino médio, por exemplo, eram realizados exames em que, juntamente com a zoologia, mineralogia, botânica, latim, matemática e química, incluem-se noções de geografia física e política” (PEREIRA, 1999, p. 42-43). Foi nesse contexto, aliás, que a Geografia universitária se expandiu, tendo em vista as necessidades escolares: "Não é, pois, como se pode pensar, a partir da universidade que a geografia alcança a rede escolar de ensino elementar e secundário, mas, ao contrário, seu desenvolvimento nestes níveis precedeu o desenvolvimento da geografia no ensino superior" (PEREIRA, 1999, p. 43). Segundo Goodson (1990), o mesmo pode ser dito do seu ensino na Inglaterra. 
Quanto ao Brasil, é imprescindível frisar que os primeiros cursos superiores de formação de professores de Geografia somente vieram a se concretizar na década de 1930, através da criação da USP, em 1934, em São Paulo, e da Universidade do Distrito Federal, no Rio de Janeiro, em 1935. Todavia, é mister reconhecer que, em período pretérito, a Sociedade de Geografia do Rio de Janeiro não apenas ofertou um curso de formação de professores como organizou congressos nacionais de Geografia em que havia espaço para a apresentação - diga-se de passagem, crescente - de trabalhos especificamente produzidos por professores da disciplina (FERNANDES, 2002). É interessante apontar que as finalidades e os propósitos do ensino da disciplina no Brasil guardavam uma associação com as especificidades do processo de formação do Estado e da Nação brasileiros. Nesse tocante, fizeram-se presentes intelectuais que, a exemplo de Everardo Backheuser e Delgado de Carvalho, propuseram-se a colaborar para a sua tomada de rumo àquela época, isto é, nas primeiras décadas do século XX (ANSELMO, 2002). Consequentemente, a Geografia, seja aquela cultivada no meio escolar, seja aquela difundida no Ensino Superior, colaborou sobremaneira para o processo de modernização da sociedade brasileira. Muito embora as escolas francesa e alemã em muito iluminaram a trajetória da institucionalização da Geografia no país, seu processo histórico de construção é peculiar e na sua amálgama podem ser identificados componentes genuinamente brasileiros.

\section{A disciplina escolar e a transposição didática}

A presença e a expansão do ensino da Geografia nas escolas guardam estreita relação com o propósito de universalização da educação, próprio da modernidade. Isso não significa, contudo, que seu ensino não tenha ocorrido em períodos anteriores. Afinal, "as escolas, no sentido de instituições formais nas quais se ensinam determinadas ideias e técnicas a crianças e adolescentes, existem na Europa Ocidental desde os tempos dos gregos e dos romanos" (GRAVES, 1985, p. 49). Por certo que os conteúdos ou saberes daquela época que pudessem vir a ser classificados como 'geográficos' se davam em quantidade variável e guardavam certa aproximação com uma 'cosmografia'. Certamente que, diante das finalidades de formação de clérigos e funcionários na Idade Média, por exemplo, as demandas por estudos de Geografia eram reduzidas, mesmo porque as chamadas sete artes liberais predominaram durante o medievo e influenciaram um largo período da história da educação ocidental. Trata-se "do trivium, formado pela gramática, retórica e dialética, e o quadrivium, formado pela aritmética, geometria, música e astronomia" (GRAVES, 1985, p. 49).

No Brasil, a Geografia se faz presente no currículo escolar desde longa data. Tomando-se como referência o Imperial Collegio Pedro II, fundado em 1837, já decorreram mais de 180 anos. Muito embora essa instituição tenha sido inicialmente criada para o ensino secundário, é necessário salientar que existiam na época as chamadas escolas isoladas, nas quais funcionavam os cursos de primeiras letras. Como se sabe, 
liquidado o sistema educacional jesuítico em 18 de junho de 1759, através de um alvará, tratou-se de reorganizá-lo por meio de aulas e classes. Contudo, somente em 1772 uma ordem régia estabeleceu as aulas de primeiras letras, que eram ministradas nas casas-grandes, em escolas e nas casas dos professores. A partir de 1893 são regulamentados os grupos escolares, que, paulatinamente, ultrapassam a matrícula das escolas isoladas (CASTANHO, 2004; VIDAL, 2006). Qual Geografia se ensinava nesse remoto período? Os professores contavam com alguma formação?

A história da formação de professores no Brasil abarca um vasto período histórico e remonta aos tempos da Colônia, quando a operacionalização do ensino e a preparação do professor para o seu exercício ficavam por conta dos jesuítas. Em momento posterior à expulsão da Companhia de Jesus (1759), escolas confessionais vinculadas aos carmelitas, aos beneditinos e aos franciscanos contavam em seus quadros com professores religiosos, e alguns professores leigos despreparados também fizeram parte desse momento bastante desarticulado do ensino no Brasil. Em 1760, deu-se o primeiro concurso para professores públicos, cujos candidatos solicitavam uma licença para ensinar mediante alguns critérios. Após a Independência, observa-se uma maior preocupação com a educação, mas nem por isso com a formação de professores, haja vista a não obrigatoriedade de formação escolar para professores concursados (CASTANHO, 2004). Somente com a criação da primeira Escola Normal do Brasil, em 1835, em Niterói, é que se abriu espaço para que os interessados no exercício do magistério se habilitassem. Como já mencionado, a formação específica em Geografia ganhou corpo em congressos nacionais, como os organizados pela Sociedade de Geografia do Rio de Janeiro no início do século XX. A partir da década de 1920, a formação de professores em nível superior dá seus primeiros passos, através da criação do Curso Livre de Geografia Superior (1926), sob a batuta de Delgado de Carvalho e Everardo Backheuser (ANSELMO, 2003).

É importante assinalar que, assim como ocorria no Brasil, em finais do século XIX havia países como os Estados Unidos, a França e o Reino Unido em que também se verificava uma certa desvalorização ou abandono do ensino da Geografia nas escolas. Contudo, personalidades do meio acadêmico, como Auguste Himly e Vidal de La Blache (França), Halford John Mackinder (Reino Unido) e William Morris Davis (Estados Unidos), foram decisivos em seus países para a valorização da Geografia no Ensino Superior, com desdobramentos positivos nas escolas (GRAVES, 1985). Reconhece-se, com isso, que ao mesmo tempo em que a demanda por professores de Geografia para atuar na Educação Básica foi determinante para a expansão da ciência geográfica nas universidades, a formação em nível superior repercutiu positivamente no desenvolvimento de programas escolares de Geografia e de práticas pedagógicas mais valorizadas. Não se trata, nesse contexto, de qualificar a relação entre a Geografia Escolar e a Geografia Universitária na perspectiva ou em termos do modelo transpositivo. Mesmo porque a elaboração teórica da transposição 
didática acontece em plena década de 1970, em um contexto histórico específico e diante de demandas próprias da época.

Para o pesquisador francês André Chervel, a disciplina escolar somente adquiriu seu sentido atual a partir da segunda metade do século XIX, e a criação do termo deu-se em 1910 (CHERVEL, 1990). Árduo defensor da ideia de que a disciplina escolar deve ser estudada historicamente, o autor sustenta que ela deva ser situada, datada e conotada. Concebida e investigada nessa perspectiva, a disciplina escolar deixa de circunscrever-se apenas ao domínio de um dado conhecimento, incorporando ao seu atual sentido finalidades, conteúdos, métodos e resultados. Assim entendida, a disciplina escolar é não só resultante como também resulta em uma cultura escolar, portanto é detentora de uma autonomia relativa. Isso significa reafirmar que possui objetivos próprios, os quais em inúmeros casos não se coadunam com os da ciência de referência, isto é, com os do conhecimento científico.

Por outro lado, a recente teorização acerca da relação entre o conteúdo disciplinar e o conhecimento de referência, encabeçada pelas didáticas específicas, atribui um valor expressivo à chamada transposição didática, o que demanda igualmente situá-la historicamente.

Segundo Belhoste (1995), as didáticas específicas, ao analisarem o processo que transforma um saber dado em um saber transmissível em ambiente escolar, valiam-se da noção de transposição didática, introduzida em 1975 pelo sociólogo francês Michel Verret. Da mesma forma que a disciplina escolar compõe um campo de pesquisa, a saber, o da história das disciplinas escolares, Verret propôs aplicar sua teoria à história das disciplinas (BELHOSTE, 1995). Entre os exemplos históricos de transposição didática, o autor cita o "latim clássico" transposto em "latim escolar" nos colégios do século XVII.

Transcorridos poucos anos, o matemático e didata da matemática, o francês Yves Chevallard, retoma e sistematiza a ideia de transposição didática. Muito embora a ideia que equivocadamente se faça de transposição didática fique resumida a mera didatização para o meio escolar dos conhecimentos produzidos na Universidade, não pode ser desconsiderada a existência de sérias questões no tocante à sua teorização, reforçando o caráter polêmico do tema. Segundo Belhoste (1995, p. 3),

\footnotetext{
Chevallard emprestou a noção com um objetivo preciso: construir (ou reparar) um modelo teórico que pudesse oferecer uma legitimidade científica à reflexão didática nos IRM (Institut de Recherches sur l'Enseignement des Mathématiques) quando em pleno desenvolvimento.
}

Segundo o matemático, o processo de transposição didática corresponde à transformação do objeto do saber (saber erudito) em saber a ensinar e deste em objeto de ensino (saber ensinado). Esse modelo foi da máxima importância para o sucesso da reforma do ensino no contexto das matemáticas modernas na França da época. Mesmo porque o ensino da Matemática padecia de relevância social.

Curiosamente, a Geografia passou por uma situação análoga de legitimação no Reino Unido, quando do embate acadêmico envolvendo, de um lado, os defensores da manutenção da Geografia 
Regional e, de outro, os partidários da Nova Geografia, esta última pautada em mais dados quantitativos e na construção de modelos. Segundo o pesquisador britânico Ivor Goodson (1990, p. 23), “a Geografia teve que renunciar para sempre as suas intenções pedagógicas e utilitárias". Ou seja, no Reino Unido dos anos 1960, quando a Geografia Escolar passou por séria crise, o pensamento geográfico foi colocado à prova, demandando da Geografia Universitária uma virada. Ocorre que a Escola foi levada de roldão nesse embate: "O paradoxo supremo é que a crise na Geografia Escolar no final dos anos 60 levou não a uma mudança que poderia ter envolvido mais alunos nas escolas, mas a mudanças na direção oposta em busca de aceitação acadêmica total” (GOODSON, 1990, p. 243). Essa passagem repercutiu sobremaneira na Escola, ou melhor, os esforços empreendidos para tornar-se uma disciplina acadêmica implicaram na substituição das tendências pedagógicas ou utilitárias da disciplina escolar em prol de um rigor acadêmico. Nesse sentido, em que medida o movimento de renovação da Geografia no Brasil, cujo marco é o Encontro Nacional de Geógrafos (ENG) de 1978, ocorrido em Fortaleza, pode ou não ser empregado para ilustrar a penetração da chamada Geografia Crítica no ambiente escolar?

\section{Colocando à prova o modelo transpositivo na Geografia}

Por detrás da questão “a quem cabe decidir o que se deve ensinar nas escolas?”, o modelo transpositivo recebeu um viés avaliativo desenvolvido por Circe Maria Fernandes Bittencourt, pesquisadora de História dos Currículos e História das Disciplinas Escolares, e por Francisco Rodríguez Lestegás, pesquisador da Universidade de Santiago de Compostela. Suas perspectivas sugerem que uma primeira e necessária observação deva ser direcionada para os atuais currículos dos cursos de formação de professores de Geografia. Existe, de fato, uma mútua correspondência entre as disciplinas ofertadas na Universidade e as demandas escolares? Melhor dizendo, existe viabilidade metodológica para as novas temáticas incorporadas pela Geografia Renovada ou Pós-Moderna? Quer parecer que aí reside uma importante fonte das dificuldades enfrentadas por educandos e educadores ao lidarem com temas geográficos da contemporaneidade, a exemplo das migrações e dos movimentos transfronteiriços, das novas territorialidades urbanas, dos territórios emocionais, das paisagens das sensações e dos sentidos. Persiste uma forte ausência de sincronia entre ensino escolar e pesquisa acadêmica, de modo tal que a renovação epistemológica da ciência geográfica parece distanciar-se cada vez mais de sua efetiva incorporação pelas e nas práticas pedagógicas (FILIZOLA, 2013). A título de ilustração, o depoimento extraído de um relatório de prática de docência em Geografia realizado por um acadêmico da Universidade Federal do Paraná (UFPR) é bastante conclusivo a esse respeito: 
enquadrar naquilo que é esperado pela equipe pedagógica da escola. (Licenciando do Curso de Geografia da UFPR, 2017) .

Segundo Bittencourt (2004), existem basicamente duas concepções de disciplina escolar, e elas conflitam entre si. A primeira delas considera a disciplina escolar como uma transposição didática das chamadas ciências eruditas de referência, ou seja, a disciplina escolar é concebida tão somente como uma adaptação dos saberes produzidos pela academia ao ambiente escolar. Consequentemente, fica estabelecida uma hierarquia em que a escola é uma reprodutora do conhecimento produzido pela Universidade, configurando-se a disciplina escolar numa relação de subordinação. Ademais, ao professor cabe o papel de tão somente transmitir os conteúdos escolares segundo os encaminhamentos metodológicos desenvolvidos por outrem. Com isso, sua posição no domínio das relações que se desenvolvem no interior da escola fica marcada pela passividade, quando bem se sabe que o saber docente se insere em um contexto de produção, e não de reprodução de saberes. Quanto à segunda, a disciplina escolar é considerada como um campo de conhecimento autônomo, como entidade específica. Em sua defesa, a historiadora se fundamenta no pensamento do britânico Ivor Goodson e do francês André Chervel. Ambos consideram que a formação desse conhecimento se dá por meio de outros saberes que não somente o científico. Isso significa dizer que as diferenças entre o conhecimento científico e o saber escolar são ainda mais expressivas, além de apontar a enorme complexidade existente nas relações entre ambas as disciplinas, a acadêmica e a escolar. Considerando-se que nessa concepção as disciplinas escolares são definidas historicamente, e as escolas tomadas em contextos que consideram o papel por elas exercido em cada momento histórico, então a escola passa a ser concebida como lugar de produção de conhecimentos. Consequentemente, o entendimento das disciplinas escolares não pode se dar descolado do conceito de cultura escolar.

Numa perspectiva semelhante, Lestegás (2012, p. 2) recusa "uma didática da geografia concebida como uma transformação ou transposição do saber científico até sua conversão em saber escolar". Debruçando-se sobre a problemática da construção do conhecimento geográfico escolar desde longa data, Lestegás desenvolveu uma densa discussão, na qual critica o modelo da transposição didática de Chevallard valendo-se do confronto entre a Geografia Escolar e a Geografia Acadêmica. Tomando como referência o caráter multiparadigmático da ciência geográfica, o autor alerta para o fato de que Chevallard “tinha desenvolvido o modelo da transposição didática a propósito do ensino da matemática, mas a geografia escolar constitui uma disciplina muito diferente, cujas relações com sua ciência referente são bem mais complexas" (LESTEGÁS, 2012, p. 17). Ou seja, existe uma pluralidade de tendências no âmbito da Geografia acadêmica que inviabilizaria sua transposição nos moldes propostos por Chevallard. O que se observa nos livros didáticos, ironiza o pesquisador espanhol, é uma "confusão paradigmática". 
Basta um olhar atento, por exemplo, sobre os Parâmetros Curriculares Nacionais (PCN) de Geografia e fica evidente a ausência de um referente científico que seja consensual.

Referenciando-se em Dominique Juliá, André Chervel e notadamente em François Audigier, pensadores que possuem em comum uma abordagem histórica em suas investigações acerca das disciplinas e dos saberes escolares, Lestegás revela que o conhecimento geográfico escolar procede de variadas fontes, aí incluídas as diversas Geografias científicas. Ocorre que muitos dos documentos utilizados na construção do livro didático de Geografia, se confrontados com a ciência de referência, “careceriam de legitimidade científica se nos ativéssemos às exigências do modelo transpositivo [tornando] difícil sustentar um modelo explicativo de 'aplicação descendente"” (LESTEGÁS, 2012, p. 18). Ao seu rol de argumentos, Lestegás incorpora aquilo que já foi exposto em relação ao pensamento de A. Chervel, a respeito da ideia de o conhecimento escolar ser concebido como uma produção cultural específica. Sendo assim, “sua finalidade essencial é proporcionar aos meninos e jovens a 'cultura escolar', da qual se serve a escola para cumprir a missão que a sociedade lhe confiou [...], no caso da geografia, contribuir para a construção de uma identidade coletiva e ao desenvolvimento da consciência nacional" (LESTEGÁs, 2012, p. 18). Em síntese, o pensamento do pesquisador espanhol expressa que "o conhecimento geográfico científico e o conhecimento geográfico escolar apresentam uma defasagem cronológica; têm diferentes condições de produção; diferem na organização do texto que os contém; respondem a finalidades diferentes" (LESTEGÁS, 2012, p. 11-16).

Tanto Lestegás como Bittencourt convergem quanto à existência de relações entre o conhecimento científico e o conhecimento escolar, mas ambos os autores insistem que seu entendimento deve contemplar a complexidade e a dinâmica de tais relações. Nessa perspectiva, o pensamento do historiador Fernando de Araujo Penna pode ser apontado como uma interessante contribuição para o entendimento da temática em relação ao ensino da História, ao empreender uma combinação teórica envolvendo a teoria da História e as teorizações didáticas e curriculares. Para tanto, o autor recorre a Ricoeur e Certeau para tratar da produção do conhecimento histórico, e a Chevallard para abordar a relação de uma didática geral com a Epistemologia, e daí ir "em busca de uma nova perspectiva epistemológica que possibilitasse problematizar o saber histórico sobre outras bases” (PENNA, 2014, p. 50). Sua construção teórica, portanto, ganha relevância menos pelo modelo transpositivo e mais pelo que "Chevallard chamou de problemática da utilização ou, para ampliar o escopo do problema, função social do saber” (PENNA, 2014, p. 51). Portanto, a aproximação entre a Escola e a Universidade, entre a disciplina escolar e a disciplina universitária deve ser cercada de cuidados, tendo em vista escapar das relações tiranas e verticalizadas que tão somente agravam a crise do ensino escolar. Nesse aspecto, o historiador ilumina a problemática ao afirmar que "a História não pode renunciar a dizer algo sobre os problemas contemporâneos e produzir um saber que seja significativo para a sociedade e possa ser ensinado na 
escola" (PENNA, 2014, p. 51). Esse 'recado', evidentemente, presta-se a todos os demais cursos de Licenciatura. Sendo assim, o que a ciência geográfica tem a dizer acerca de sua função social e daquilo que pode ser transmitido no ensino escolar?

\section{Em direção a uma Geografia da Educação?}

Como pode ser classificada a relação entre a ciência geográfica e a disciplina escolar geográfica? São três as tendências, o que expõe, em larga medida, quão conflituosa é a relação. Além disso, reforça a ideia de que não há um consenso acerca da questão, com significativas implicações na formação inicial dos professores da área.

Uma primeira tendência é a de conceber que existe uma correspondência direta, na qual a disciplina escolar é tida como cópia da ciência de referência. Uma segunda tendência reconhece uma visão dicotomizada, ou seja, uma cisão ou separação entre ambas. E uma terceira tendência expressa uma visão de aproximação, admitindo uma relativa correspondência entre as duas. Quer parecer que esta última seja merecedora de crédito e possa até mesmo prestar-se às ‘considerações finais' do presente texto como um todo.

Convém esclarecer de início que não se trata de eleger uma posição conciliatória a respeito da relação Universidade-Escola. Mesmo porque o saber escolar dá-se na relação com outros saberes: de um lado, aqueles dos quais procura se aproximar e, de outro, dos quais ele parte (SAVIANI, 2003). Isto é, o saber escolar com o qual a Geografia compõe suas finalidades não se constrói tão somente a partir da ciência geográfica. Quer dizer, não se trata de atribuir um peso excessivo à conversão do saber científico (erudito) em saber escolar (de ensino), mas sobretudo direcionar a reflexão para a questão que foi logo acima colocada: o que a ciência geográfica tem produzido que possa ser transmitido nas salas de aula?

Quer parecer que as pesquisas desenvolvidas no âmbito dos Programas de Pós-Graduação em Geografia e em Educação são uma referência fundamental. Contudo, ainda é escasso o número de linhas de pesquisa especificamente voltadas para o ensino da Geografia. É do conhecimento que inúmeros trabalhos investigativos envolvendo problemáticas próprias da disciplina escolar acontecem no seio de linhas que não necessariamente voltem-se exclusivamente para esse fim. Quantas linhas de pesquisa em ensino de Geografia existem no país? Considerando-se que no estado do Paraná existe apenas e tão somente uma, pode-se lançar um olhar pessimista para o restante do território nacional. É nesse contexto e com o intuito de qualificar ainda mais as pesquisas em ensino que se poderia investir mais acentuadamente na edificação de uma Geografia da Educação nos Programas de Pós-Graduação e, por que não, nos cursos de graduação em Geografia.

Resumidamente, a Geografia da Educação pode ser definida como um subcampo voltado para o ensino e a pesquisa, ambos focados em propósitos educacionais, além de teoria em Geografia, abarcando 
desde a Educação Infantil até a Pós-Graduação, em contextos formais e informais (SOLEM, 2006). A escola é um território específico. Suas fronteiras, sejam elas físicas ou emocionais, delimitam um espaço culturalmente marcado, grafado. Transpô-las representa adentrar um universo novo, no qual o jovem e a criança dão prosseguimento ao seu aprendizado. Ocorre que, se de um lado as fronteiras são passagem, encontro de culturas, de saberes e de discursos, de outro também atuam como barreiras que restringem ou enformam a entrada desses atores no espaço escolar, simbolicamente falando. Ademais, o espaço escolar é um espaço emocionalizado, portanto dotado de uma carga simbólica que repercute, igualmente, na maneira com que os jovens e as crianças adentram e circulam nesse universo. Isso significa dizer, ainda, que categorias analíticas comumente associadas à ciência geográfica, como a paisagem, o lugar, o território, a fronteira, podem se prestar para balizar os propósitos investigativos e promover o estabelecimento de interfaces entre a Geografia da Educação e, por exemplo, a Geografia Cultural.

Existem espaços difíceis de pensar e de descrever. A escola é um deles, já nos ensinou Bourdieu (2008). Sua opacidade é tanto maior quanto menor a eficiência do meio empregado para conhecê-la ou compreendê-la. Mesmo porque esses espaços meio que se esquivam do observador, como que se se negassem a ser interpretados, recusando-se a serem captados em um dado instante. À semelhança das imagens criadas em um caleidoscópio, a escola, se tomada numa única visada, tão somente na sua aparência, não pode ser apreendida na sua totalidade. Tomá-la na superficialidade certamente não nos conduzirá a um horizonte suficientemente aberto, capaz de nos levar, "nós, observadores externos", a perceber os sentidos que os atores sociais que nela circulam atribuem ao espaço. Assim, pode a Geografia da Educação contribuir para uma leitura mais profunda e densa do espaço escolar e das questões a ele vinculadas? De quais metodologias próprias da pesquisa educacional lançar mão?

Uma Geografia de fato Escolar possui certa autonomia diante da ciência de referência. O saber escolar, em sua relação com outros saberes e conhecimentos, contempla os mitos, os princípios religiosos, a crença no sobrenatural. Evidentemente que tais formas de conhecimento conflitam com outras mais elaboradas. Mas é do conflito que surge o novo. É esse o fato que permite aos educandos se apropriarem de um saber novo porque reelaborado. Portanto, a relação entre a disciplina escolar e a disciplina acadêmica pode ser reorientada tendo-se em conta que os jovens educandos, verdadeiros destinatários e usuários dos conteúdos escolares, merecem experienciar diferentes e múltiplas abordagens. Talvez suas percepções possam servir para que novos programas escolares sejam esboçados. A realidade das ruas do nosso país, no momento presente, parece sinalizar muitas coisas. Não seria o caso de criar situações que possam dar mais voz aos educandos? Nessa perspectiva, as múltiplas Geografias podem proporcionar um ‘automapeamento’ capaz de inspirar currículos ou programas em que alunos e professores sejam seus maiores protagonistas. 


\section{Referências}

ANDERSON, B. Comunidades Imaginadas: reflexões sobre a origem e a difusão do nacionalismo. São Paulo: Companhia das Letras, 2008.

ANSELMO, R. C. M. de S. A formação do professor de Geografia e o contexto da formação nacional brasileira. In: PONTUSCKA, N. N.; OLIVEIRA, A. U. de (Orgs.). Geografia em perspectiva. São Paulo: Contexto, 2002. p. 247-253.

AZEVEDO, A. de. O Brasil e suas regiões. São Paulo: Companhia Editora Nacional, 1972.

BELHOSTE, B. Resume de l'exposé de Bruno Belhste au Service d'Histoire de l'Education. Paris: INRP, 1995.

BITTENCOURT, C. M. F. Ensino de História: fundamentos e métodos. São Paulo: Cortez, 2004.

BOURDIEU, P. (Org.) A miséria do mundo. 7. ed. Petrópolis: Vozes, 2008.

BRUTER, A.; LOCHER, F. Disciplinas escolares. In: VAN ZANTEN, A. Dicionário de Educação. Petrópolis: Vozes, 2011.p. 239-242

BURKE, P. Uma história social do conhecimento: de Gutenberg a Diderot. Rio de Janeiro: Jorge Zahar, 2003.

CARVALHO, D. de. Methodologia do ensino geográfico: introdução aos estudos de Geographia Moderna. Petrópolis: Tipographia da Vozes de Petrópolis, 1925.

CASTANHO, S. E. M. A educação escolar pública e a formação de professores no Império brasileiro. In: LOMBARDI, J. C.; NASCIMENTO, M. I. M. (Orgs.) Fontes, história e historiografia da educação. Campinas: Autores Associados, 2004. p. 37-63.

CAVALCANTI, L. de S. Geografia e práticas de ensino. Goiânia: Alternativa, 2002.

CHERVEL, A. História das disciplinas escolares: reflexões sobre um campo de pesquisa. Teoria \& Educação, Porto Alegre, n. 2, p. 177-229, 1990.

FERNANDES, M. Reflexões sobre a investigação em história da formação de professores de Geografia. In: PONTUSCKA, N. N.; OLIVEIRA, A. U. (Orgs.). Geografia em perspectiva. São Paulo: Contexto, 2002. p. 241 246.

FILIZOLA, R. O ensino da Geografia: em direção a uma perspectiva emocional. In: PONGETTI, C. et al. (Orgs.). Dalle Marche al mondo: i percotrsi di um geografo. Scritti in onore di Peris Persi. Urbino: Università degli Studi di Urbino "Carlo Bo", 2013. p. 153-162.

GOODSON, I. Tornando-se uma matéria acadêmica: padrões de explicação e evolução. Teoria \& Educação, Porto Alegre, n. 2, p. 230-254, 1990.

GOODSON, I. Currículo: teoria e história. Petrópolis: Vozes, 1995.

GRAVES, N. J. La enseñanza de la geografía. Madrid: Visor Libros, 1985.

LACOSTE, Y. A Geografia: isso serve, em primeiro lugar, para fazer a guerra. Campinas: Papirus, 1988.

LESTEGÁS, F. R. A construção do conhecimento geográfico escolar: do modelo transpositivo à consideração disciplinar da Geografia. In: CASTELLAR, S. M. V.; MUNHOZ, G. B. (Orgs.). Conhecimentos escolares e caminhos metodológicos. São Paulo: Xamã, 2012. p. 13-27. 
MÉRENNE-SCHOUMAKER, B. Didáctica de Geografia. Porto: Asa Editores, 1999.

MONTEIRO, A. M. A prática de ensino e a produção de saberes na escola. In: CANDAU, V. M. (Org.). Didática, currículo e saberes escolares. 2. ed. Rio de Janeiro: DP\&A, 2002. p. 129-147.

PENNA, F. de A. A relevância da didática para uma epistemologia da História. In: MONTEIRO, A. M. et al. (Orgs.). Pesquisa em História: entre desafios epistemológicos e apostas políticas. Rio de Janeiro: Faperj, 2014. p. 41-52.

PEREIRA, D. Geografia escolar: uma questão de identidade. Cadernos CEDES, Campinas, n. 39, p. 47-56, dez. 1996.

PEREIRA, R. M. F. do A. Da Geografia que se ensina à gênese da Geografia moderna. 3. ed. Florianópolis: UFSC, 1999.

PERES, E. A escola graduada no Rio Grande do Sul no início do século XX: a implantação de um novo modelo e de uma nova cultura escolar. In: VIDAL, D. G.; SCHWARTZ, C. M. (Orgs.). História das culturas escolares no Brasil. Vitória: Ufes, 2010. p. 59-93.

SANTOS, M. A natureza do espaço: técnica e tempo, razão e emoção. São Paulo: Hucitec, 1996.

SAVIANI, N. Saber escolar, currículo e didática. 4. ed. Campinas: Autores Associados, 2003.

SOLEM, M. Geography Education. In: WARF, B. (Ed.). Enciclopedia of Human Geography. Thaousand Oaks: SAGE Publications, 2006. p. 182-184.

VIDAL, D. G. (Org.) Grupos escolares: cultura escolar e escolarização da infância no Brasil (1893-1971). Campinas: Mercado de Letras, 2006.

VIDAL, D. G.; SCHWARTZ, C. M. Sobre cultura escolar e história da educação: questões para debate. In: VIDAL, D. G.; SCHWARTZ, C. M. (Orgs.) História das culturas escolares no Brasil. Vitória: Ufes, 2010. p. 13 35. 